\title{
Desenvolvimento de Mobiliário Multifuncional para Espaços Reduzidos
}

\author{
Development of multifunctional furniture for small spaces
}

SILVA, lanka Martins Carvalho; Graduação em Design; UFSC

MEDEIROS, Ivan Luiz; Doutor em Design; UFSC

\begin{abstract}
Resumo
Este artigo apresenta o processo de desenvolvimento de um mobiliário multifuncional destinado a ambientes compactos, priorizando técnicas destinadas à fabricação digital. Tem-se a finalização em um modelo físico que atenda às necessidades do público-alvo utilizando a metodologia de inovação de Kumar, 'Os sete modos de processo de Inovação'. O projeto priorizou problemas de desconforto encontrados nesses espaços menores, facilitando o dia-a-dia do usuário. Por meio de uma pesquisa quantitativa com o público alvo identificou-se o quarto como o cômodo mais utilizado direciona-se o projeto para esse ambiente. Com a pesquisa etnográfica foi possível observar as principais tarefas realizadas nesse ambiente íntimo e identificar suas necessidades. 0 processo de geração de alternativas e testes com mock-ups resultou em uma Escrivaninha Multifuncional "Pôr do Sol", que atende aos conceitos gerados de multifuncionalidade, praticidade e aconchego bem como as funcionalidades principais de estudar, organizar e decorar.
\end{abstract}

Palavras Chave: mobiliário; multifuncionalidade; ambientes compactos e fabricação digital.

\begin{abstract}
This article presents the process of developing a multifunctional furniture designed for compact environments, prioritizing techniques designed for digital fabrication. We have the finalization in a physical model that meets the needs of the target audience using Kumar's innovation methodology, ' The seven Modes of innovation process '. The project prioritized discomfort problems encountered in these smaller spaces, facilitating the user's day-to-day. By means of a quantitative survey with the target audience, the room was identified as the most used rooms are directed to the project for this environment. With ethnographic research it was possible to observe the main tasks carried out in this intimate environment and identify their needs. The process of generating alternatives and testing with mock-ups resulted in a multifunctional "sunset" desk, which meets the concepts generated from multifunctionality, practicality and coziness as well as the main features of studying, organizing and decorate.
\end{abstract}

Keywords: furniture; multifunctionality; compact environments and digital fabrication. 


\section{Introdução}

O mercado de mobiliário está na 10 a colocação entre os empreendimentos que mais dão certo no mundo todo, gerando cada vez mais empregos e rendimento para a população (LAM; ZUINE, 2016). Juntamente com esse crescimento, o polo moveleiro catarinense teve um aumento de exportação considerável em relação aos anos anteriores, com o aumento do dólar, para a Europa e Estados Unidos (RBS TV, 2015). O design como papel importante, vem para criar e diferenciar o produto a ser comercializado, pensando não somente na estética, mas na funcionalidade, conforto e necessidades do usuário (BARROSO, 2007).

Observa-se espaços residenciais cada vez mais reduzidos tanto em apartamentos quanto em casas, o que parece caracterizar o novo estilo de vida contemporâneo. Ambientes estão cada vez mais compactos, sendo tendência em todo o Brasil, com ênfase no sul do país (Revista EDIFICAR, 2017). Isso fez com que construtoras avistassem um mercado favorável, onde pode-se ter mais apartamentos em um mesmo edifício, tendo mais lucro com pouco consumo de espaço (Revista ZAP, 2016). Essa nova cultura de ambientes limitados, faz com que o design venha a se adaptar a essa premissa. Planejando o aproveitamento de espaços, com móveis mais compactos, agregam-se múltiplas funcionalidades no mesmo produto, assim proporcionando praticidade aos usuários que possuem cada vez menos tempo no seu dia a dia.

Hoje, os projetos não são somente criados digitalmente, mas também produzidos digitalmente, seja pela prototipagem rápida ${ }^{1}$ ou por processos de fabricação digital ${ }^{2}$ sendo numericamente controlados por computador (CNC), comumente chamados de processos "file-tofactory" (PUPO, 2011). A tradução literal do processo "file-to-factory" como sendo "do arquivo para a fábrica", se caracteriza quando o modelo digital 3D se comunica diretamente com as máquinas programáveis (MEDEIROS et al., 2014).

Dessa forma, este artigo apresenta o processo de desenvolvimento de um mobiliário multifuncional que se adeque a espaços reduzidos, de forma que faça com que o usuário se sinta confortável no ambiente, ajudando na sua praticidade do dia-a-dia. Busca-se criar um produto visando as características do público, e a utilização de materiais e formas que ajudem a tornar aconchegante o espaço já limitado. Pensando no processo de produção por fabricação digital presente em FabLabs e que ajudam na diminuição do desperdício de matéria-prima.

${ }^{1}$ O termo prototipagem rápida designa um conjunto de tecnologias usadas para se fabricar objetos físicos diretamente a partir de fontes de dados gerados por sistemas de projeto auxiliado por computador (CAD). Tais métodos são bastante peculiares, uma vez que eles agregam e ligam materiais, camada a camada, (sistemas aditivos) de forma a constituir o objeto desejado (GORNI, 2001).

2 Os equipamentos que fazem parte das tecnologias de fabricação digital são associados aos sistemas de controle numérico computadorizado (CNC). Os principais tipos são as cortadoras laser, as routers e as impressoras tridimensionais, que interpretam modelos digitais fazendo a transposição do virtual para o material de forma precisa e direta. Facilitando a prototipagem quanto a produção de produtos customizados (COSTA-NETO, et al., 2015) e (ALVARADO e BRUSCATO, 2009). 


\section{Metodologias e Processos}

O processo projetual que será aplicado ao artigo é o modelo 'Os sete modos de processo de Inovação' desenvolvido por Vijay Kumar autor do livro 101 Design Methods e professor do IIT Institute of Design do Illinois Institute of Technology.

Esse modelo de processo de inovação no design é cíclico, prescritivo e descritivo, e está dividido em cinco fases: Intenção (Sense Intent), Pesquisa (Research), Análise (Analysis), Síntese (Synthesis) e Concepção (Realization) e conta com 7 maneiras diferentes de planejamento: Intenção (Sense Intent), Conhecer o Contexto (Know Context), Conhecer o Usuário (Know People), Quadro de Insights (Frame Insights), Exploração de Conceitos (Explore Concepts), Quadro de Soluções (Frame Solutions), e Percepção (Realize Offerings). Cada modo possui seus próprios objetivos e atividades que podemos observar na figura 1 (KUMAR, 2012).

Figura 1 - Modelo 'Os sete modos de processo de Inovação'

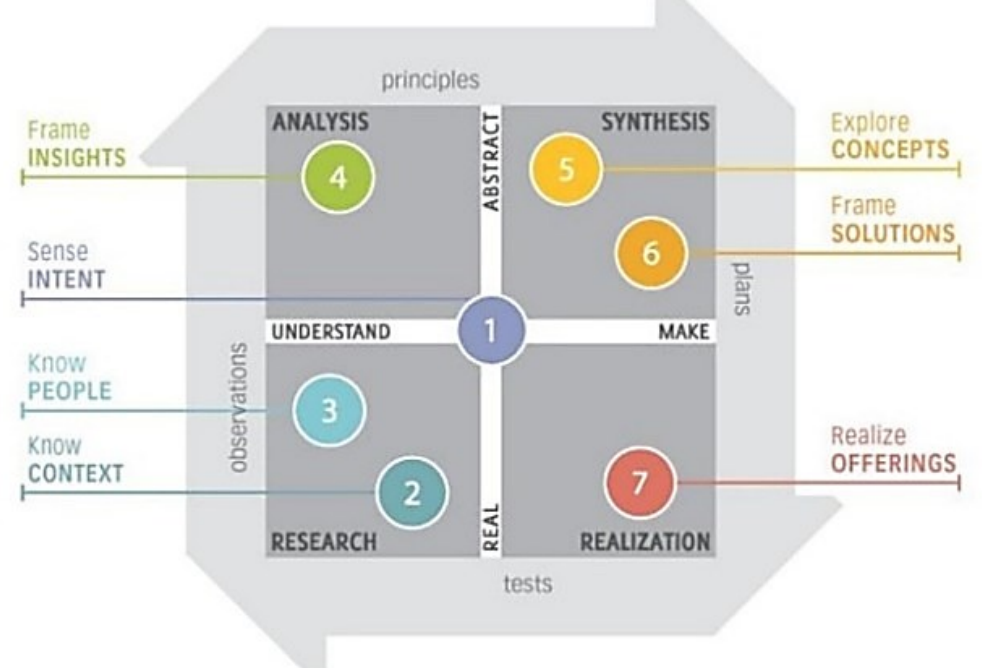

Fonte: KUMAR, 2012.

Segundo Kumar (2012), o primeiro estágio de Intenção inicia-se uma pesquisa geral entre os últimos acontecimentos na sociedade, na cultura, na política, nos negócios, na tecnologia, entre outros contextos, com o intuito de se obter as principais tendências em vigor focando no tema que se quer atingir. Assim pode-se ter a intenção inicial de como resolver a problemática em questão com mais possibilidades de gerar inovação no projeto.

No segundo passo de Conhecer o Contexto, está voltado a conhecer onde o produto está ou estará inserido compreendendo o ambiente, analisando os concorrentes e similares. Estar a par de eventuais problemas que podem vir a afetar o propósito de inovação, e que afetam projetos semelhantes ao tema (KUMAR, 2012).

A próxima fase de inovação é Conhecer o Usuário, onde se tem o objetivo de saber informações verdadeiras sobre o público-alvo, que podem ser obtidas de forma mais consistente e 
qualitativa, através de observação e pesquisa etnográfica que difere dos resultados de pesquisa apenas por questionários. É a fase que também se define o consumidor que se quer atingir, e possivelmente onde se pode respingar.

Em seguida o Quadro de Insights que nada mais é que o modo de síntese dos dados já obtidos. Onde se agrupa e organiza todas as informações já coletas, podendo visualizar melhor as partes que se encaixam, encontrar padrões, e relembrar resultados de métodos anteriores não deixando passar nenhuma informação que possa ser benéfica para gerar inovação (KUMAR, 2012).

Na Exploração de Conceitos, no quinto passo, é gerado o conceito a partir do Quadro de Insights, amarrando bem os objetivos do projeto com as necessidades do público-alvo. Nesta fase também é comum o uso de um Brainstorming desenvolvendo novas ideias e oportunidades.

No penúltimo passo, já em fase final do método de inovação em design o Quadro de Soluções avalia os conceitos gerados analisando junto com as informações obtidas. Faz-se um teste com protótipos para obter um feedback com o usuário tornando as soluções visíveis e táteis, observando e comparando com os requisitos e informações sintetizadas até essa etapa, escolhendo as opções que melhor se encaixam com o tema (KUMAR, 2012).

E finalizando o método de Kumar (2012), a fase se Percepção é a concepção final do produto, avaliação da empresa e viabilidade de produção.

Será aplicado ao decorrer deste artigo algumas fases da metodologia detalhada, com o objetivo de projetar um mobiliário que atinja o tema proposto com o intuito de gerar inovação em design.

\section{Matéria-prima e Fabricação}

Segundo Lima (2006) o material mais antigo utilizado pelo homem é a madeira, por sua fácil fabricação uma vez que explorada de forma correta em reservas de reflorestamento e a flexibilidade para ser trabalhada.

A madeira é considerada a matéria-prima essencial para obtenção dos móveis, suas propriedades são diversificadas como a leveza e rigidez, é forte e dura. Seu custo é relativamente barato, e é um material fácil de esculpir desenhos e formas, unir-se a outras partes e usina-la (MARCELLI, 1997 e ASHBY, JOHNSON, 2011).

A montagem dos móveis de madeira muitas vezes é feita com encaixes com a cavilha e a respiga. A cavilha sendo uma peça cilíndrica de madeira ou plástico, com estrias que pode ser unida por pressão e ou cola em rebaixos cilíndricos nas peças do móvel, ilustrado na figura 2. 
Figura 2 - Sistema junção por respiga e cavilha

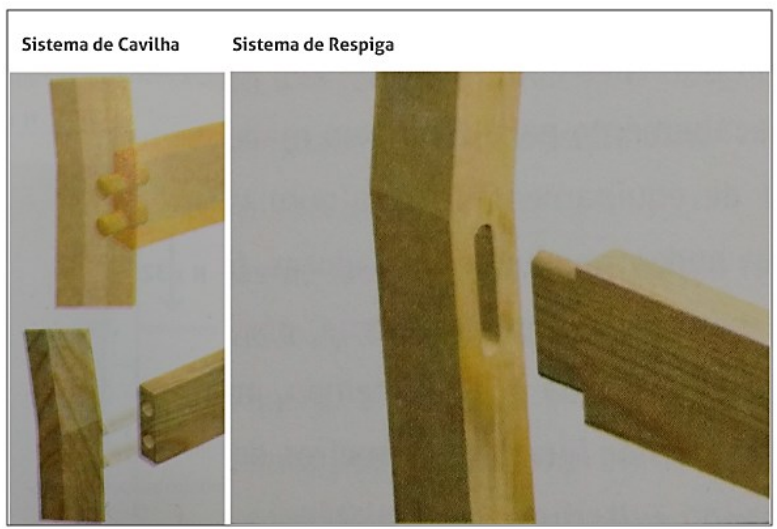

Fonte: LIMA, 2006.

A união mecânica por respiga ilustrada na figura $x$ consiste em uma peça 'macho' com forma alongada e outra peça 'fêmea' um rebaixo negativo da outra peça, que são conectadas por pressão. É um sistema de montagem mais fácil e muitas vezes intuitivo, além de elevar a resistência do material (LIMA, 2006).

Com a industrialização o processo de produção de móveis vem sendo eficiente e rápido deixando de lado os tradicionais encaixes de marcenaria. Mas com a tecnologia das maquinas CNC (Comando Numérico Computadorizado) é possível utilizar dessa técnica em alguns móveis (BARATTO, 2016). Como apresentado na figura 3 alguns encaixes usinados na CNC.

Figura 3 - Técnicas de corte na CNC para encaixes na madeira.

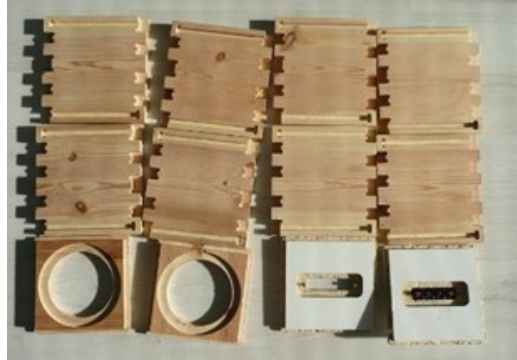

Fonte: Da autora

\section{Métodos e Ferramentas}

Neste próximo capítulo são apresentadas algumas ferramentas do processo de desenvolvimento de produto através da metodologia de Kumar (2012). A primeira etapa é a fase de pesquisa do produto conhecendo as possibilidades do tema através de um mapa mental, o questionário como pesquisa quantitativa a fim de definir o público, a pesquisa etnográfica focada no usuário estabelecendo suas necessidades e multifuncionalidades do produto.

\subsection{Mapa Mental}

A primeira etapa do desenvolvimento consiste na técnica do mapa mental que nada mais é 
que um método de organização das ideias de projeto por meio de um tema central que se ramifica através de palavras chaves. É aconselhável para um bom fluxo de criação, a utilização de cores, imagens, símbolos etc (PAZMINO, 2013).

Iniciando com 'Mobiliário multifuncional para espaços reduzidos' ao centro, o mapa mental exibido na figura 4 foi ramificado a partir de critérios a serem desenvolvidos como: Como?; Onde?; Público; Materiais; Acabamento; Ergonomia; e Design.

Figura 4 - Mapa Mental

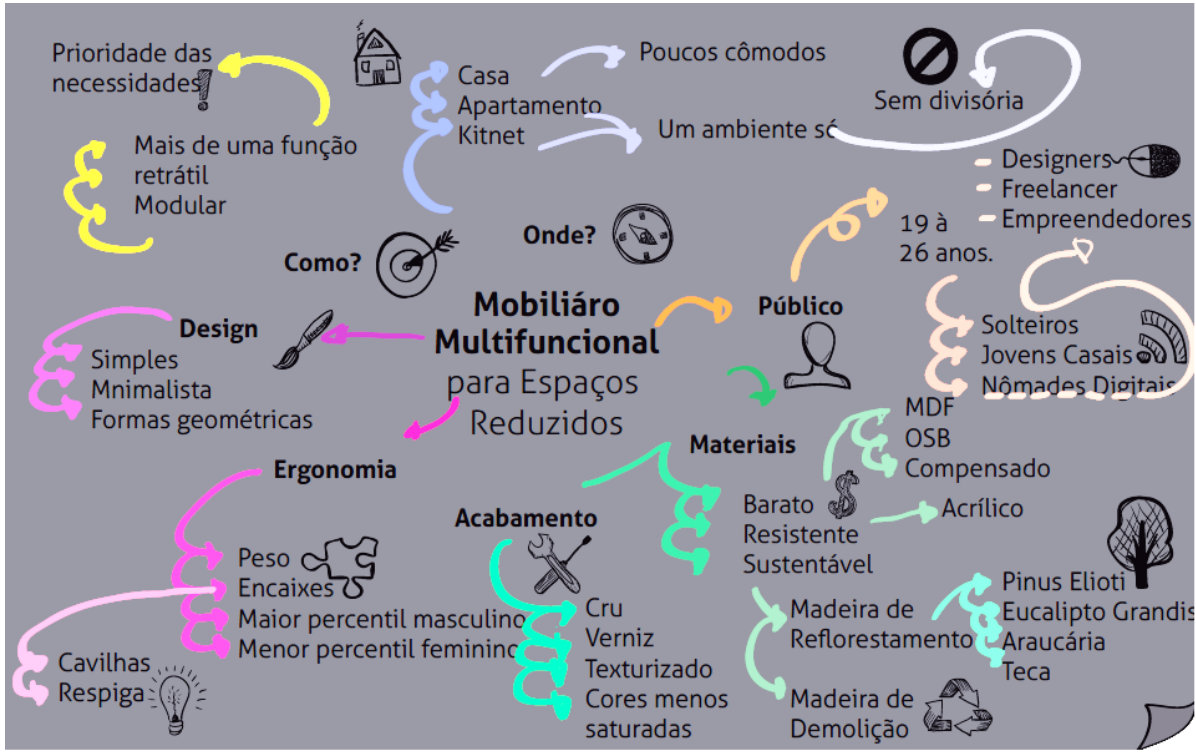

Fonte: Da autora.

\subsection{Pesquisa do Público}

Uma das formas de levantar as necessidades e desejos do cliente é a partir de uma pesquisa quantitativa, que é mais objetiva e quantifica como os consumidores preferem determinado produto ou serviço (PAZMINO, 2013).

Foi realizada uma pesquisa com o público-alvo através de um questionário online no período de 16/05/2017 à 22/05/2017, disponibilizado nas redes sociais, em grupos de alunos da Universidade Federal de Santa Catarina - UFSC e grupos de design de produto, em um total de 60 respostas.

A partir da pesquisa de questionário online, junto com a tabulação das respostas obtidas foi possível conhecer as necessidades do consumidor. Esse método para Pazmino (2013) visa entender os desejos do usuário, e percepções que ele tem em relação ao tema abordado. $\mathrm{Na}$ figura 5 as necessidades encontradas: 
Figura 5 - Lista de Necessidades

\begin{tabular}{|c|l|}
\hline ASPECTOS & \\
\hline FABRICAÇÃO & Peças desmontáveis; Fácil montagem; \\
\hline AMBIENTE & $\begin{array}{l}\text { Produto para o quarto; Poupar espaço; Ajudar na organização; Espaço para } \\
\text { estudar; Estar conectado. }\end{array}$ \\
\hline MATERIAL & Materiais resistentes; Fácil limpeza. \\
\hline DESICN & Customizável. \\
\hline ERCONOMIA & Leve; Fácil deslocamento da peça. \\
\hline
\end{tabular}

Fonte: Da autora

Através dessas necessidades é possível trabalhar especificamente onde o usuário possui desejos e carências. As observações indicaram que seria mais adequado o mobiliário multifuncional projetado para o ambiente do quarto, onde o público-alvo passa mais tempo. Buscar-se-á opções por materiais mais resistentes de acordo com a função destinada, acessórios e peso que facilitem a locomoção do produto para a limpeza e mudança de sua localização no ambiente.

\subsubsection{Pesquisa Etnográfica}

A terceira fase de planejamento da metodologia aplicada consiste em conhecer o usuário, onde foi realizada uma pesquisa etnográfica a fim de compreender melhor o público-alvo em busca de informações qualitativas, dentro do ambiente em que estes passam mais tempo. Duas mulheres, Aline de 26 anos e Denise de 21, foram observadas durante o período diurno em suas residências compactas realizando tarefas em seus respectivos quartos.

A primeira pessoa (Aline) possui um quarto de $12 \mathrm{~m}^{2}$ (Figura 6) que divide com seu marido onde contém: um guarda-roupa feito em casa com uma disposição de prateleiras e cabides customizada, pois em uma loja ela diz que não conseguiria um tamanho tão compacto que coubesse tudo o que precisa, como o móvel é aberto consegue ter uma boa visibilidade das roupas mas acaba por acumular muita poeira; uma sapateira; um criado mudo ao lado da cama onde costuma deixar sempre o notebook. 
Figura 6: Esquema do quarto 1 (Aline); Esquema do quarto 2 (Denise)
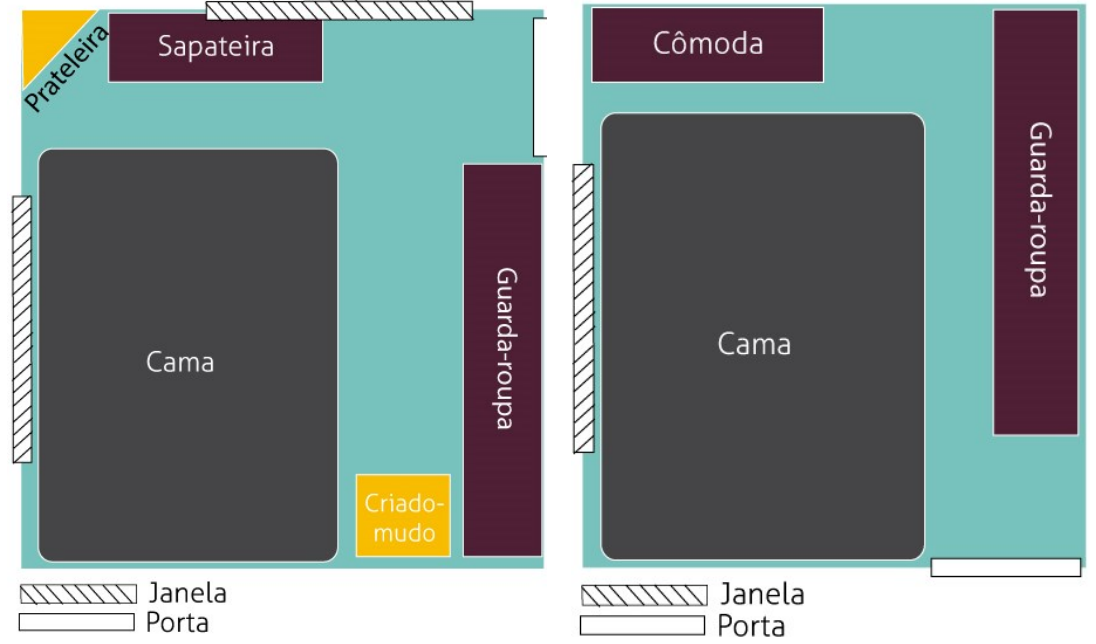

Fonte: Da autora

Outras características interessantes observadas é que o usuário gosta de expor fotos e quadros no ambiente, mas não possui muito espaço de decoração além das paredes. Não muda os móveis de lugar com frequência devido ao peso do mobiliário e estrutura fixa.

Já na segunda pesquisa de observação o usuário (Denise) possui um quarto de $10 \mathrm{~m}^{2}$, esquema na figura 6 . Sua mobília contém um guarda-roupa de 6 portas; uma cama de casal, com uma TV em sua base que é bastante utilizada. A disposição dos móveis não costuma ser modificada por conta da falta de espaço e peso dos materiais. Ela não consegue espalhar objetos decorativos pelo ambiente por falta de onde por.

Foi feita a pesquisa etnográfica em dois cômodos de usuárias distintas que possuíam paredes como divisória de ambientes para observar as tarefas e dificuldades diárias do públicoalvo, mas o produto final é desenvolvido para estar inserido em apartamentos e casas de no mínimo $40 \mathrm{~m}^{2}$ com pouca ou nenhuma divisória de cômodos facilitando o uso do produto.

Através desta pesquisa é possível reafirmar as multifuncionalidades necessárias para o produto desenvolvido neste artigo que consiste em: espaço para estudar, disponibilidade para decoração e ajudar na organização. Onde o produto final deseja atender todas ou algumas funcionalidades encontradas através da pesquisa a fim de suprir as carências do público-alvo.

\subsubsection{Estilo de Vida do Público-Alvo}

O público-alvo destinado ao projeto consiste em pessoas de ambos os sexos, homens e mulheres, de 19 a 26 anos, que estudam em faculdade fora de sua cidade, recém-formados em design, freelancer e empreendedores. São na sua maioria de estado civil solteiro, ou jovens casais que estudam e ou trabalham, residentes nas regiões de Santa Catarina e São Paulo, classe social C e B. Moram em apartamentos compactos, com poucas ou sem divisórias dos ambientes. Ativos social e economicamente, conectados, viajam para outras regiões com foco no trabalho e 
experiências profissionais. Utilizam na maior parte transporte público e possuem tempo para o lazer limitado.

O painel semântico do estilo de vida mostrado na figura 7 tende a ilustrar o comportamento do usuário, seu perfil social, cultural criando sua identidade.

Figura 7 - Painel Semântico do Estilo de Vida do Público-alvo

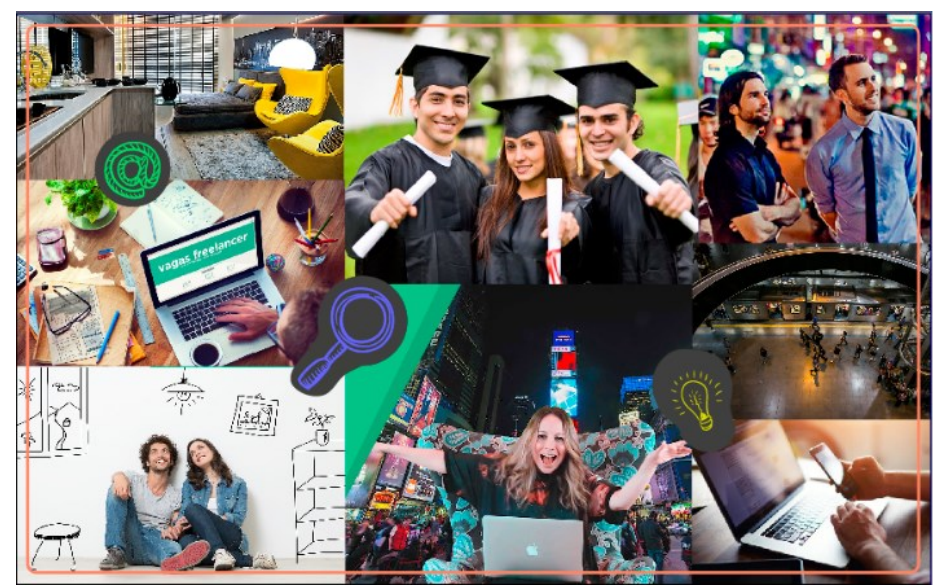

Fonte: Da autora.

\subsection{Ergonomia}

Segundo IIDA (1998) Ergonomia é o estudo da adaptação do trabalho ao homem, ou seja, estuda a relação humana com o seu meio. Ela parte das dimensões do homem para adaptar o projeto de trabalho de forma adequada, de acordo com a capacidade e limitações humanas.

Panero e Zelnik (2008), fornece parâmetros de dimensionamento humano para espaços internos, destacando-se o cômodo do quarto que foi visto na pesquisa descrita anteriormente do público alvo (pesquisa quantitativa e qualitativa) como o cômodo mais utilizado dentro do habitar compacto, para uma análise dimensional nesse projeto. Dessa maneira as dimensões mais relevantes são destacadas na figura 8 , onde há um infográfico de medidas dos principais e mais comuns móveis encontrados dentro dos espaços íntimos do usuário como observou-se na pesquisa etnográfica, de acordo com o percentil 5 a 95 do homem e da mulher. 
Figura 8 - Infográfico das medidas ergonômicas do mobiliário destinado ao quarto.

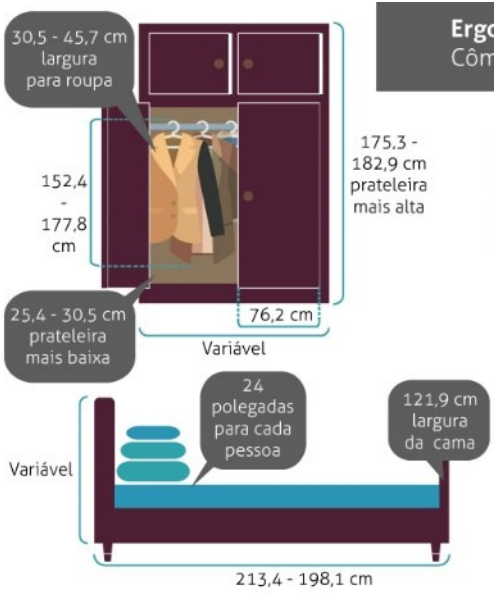

\section{Ergonomia}

Cômodo do Quarto

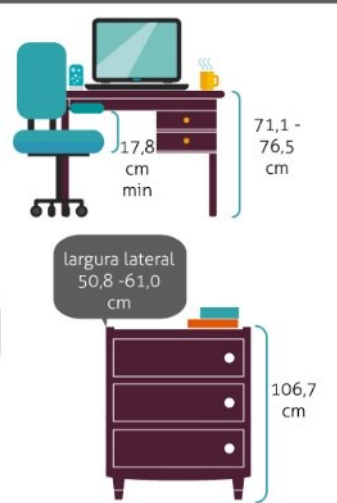

Fonte: Adaptado de PANERO e ZELNIK, 2008.

Uma cômoda com gavetas para ser aberta pelo usuário, considerando o espaço deste realizando a tarefa 121,9 a 147,3 cm para homens e 116,8 a 132,08 cm para mulher, um espaço que muitas vezes o público não dispõe. A altura desse móvel para o percentil 5 da mulher é de $106,7 \mathrm{~cm}$. A distância do topo da mesa de escrivaninha até o chão deve ficar entre $71,1 \mathrm{a} 76,5 \mathrm{~cm}$, já o espaço entre o topo inferior da mesa até superfície da cadeira deve acomodar de forma agradável a coxa do usuário $(12 \mathrm{~cm})$ sendo este de $17,8 \mathrm{~cm}$ de altura, esta medida serve para mesas de jantar, reuniões e escritório (PANERO e ZELNIK, 2008).

Ao analisar as recomendações das medidas necessárias para obter um espaço agradável dentro do cômodo do quarto nesses ambientes compactos, observa-se a importância da ergonomia em projetos de design, que muitas vezes é ignorada gerando um produto prejudicial ao usuário, acabando por não atingir a sua funcionalidade.

\subsection{Análise Estrutural}

Vista a necessidade projetual de conhecer melhor o produto a ser desenvolvido optou-se por realizar a Análise Estrutural, essa é indicada como próxima etapa depois de uma análise de uso, ela proporciona a análise de um produto concorrente, de maneira a identificar as partes, componentes e peças podendo haver um melhoramento do produto no caso de um redesign (PAZMINO, 2013).

Neste projeto foi verificado a estrutura de dois produtos similares aos vistos na análise de uso pelo público, que não é mostrada neste artigo a fim de respeitar o limite de páginas, e um móvel multifuncional. Para compreender a estrutura do mobiliário destinado ao quarto presente nas residências do usuário de classe $C$ e $B$ visto na pesquisa etnográfica a fim de observar os componentes necessários, tentando prever uma redução da quantidade de parafusos para a praticidade de montagem e produção, com a utilização de encaixes. Na figura 9 um dos produtos analisados em tabela estrutural. 
Figura 9 - Análise estrutural escrivaninha

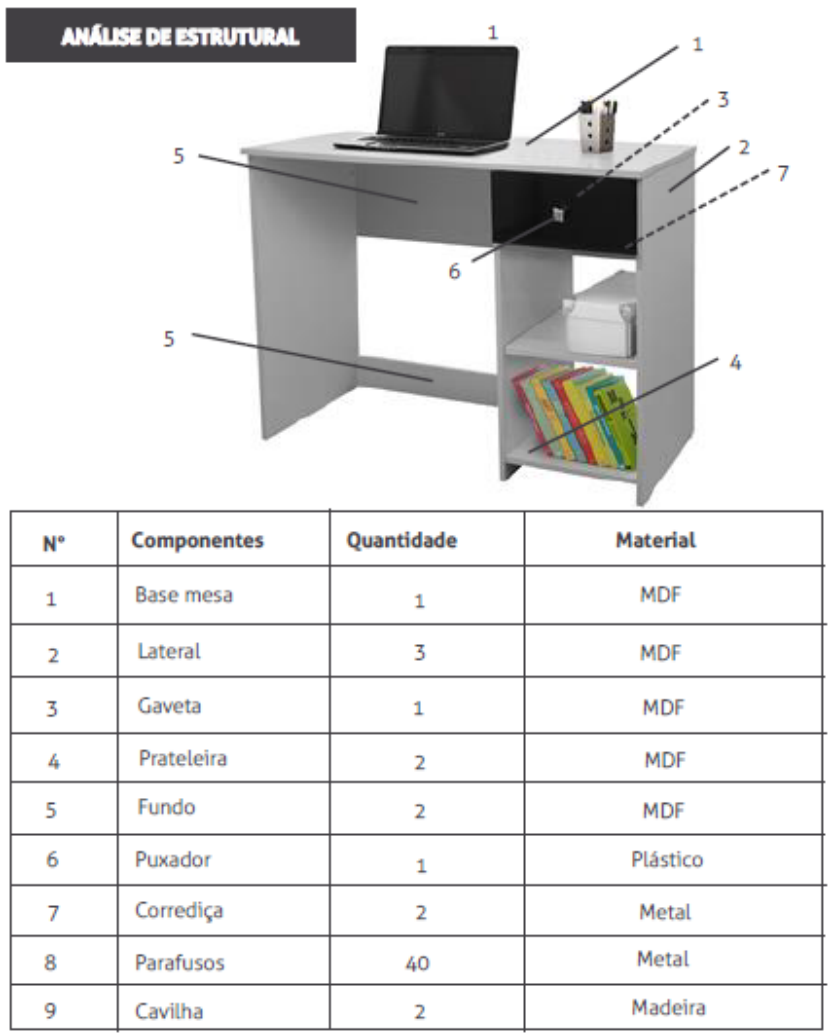

Fonte: Da autora

\section{Desenvolvimento}

Segundo Baxter (2000) a definição do conceito tem como objetivo estabelecer características para o novo produto de forma a satisfazer as necessidades do público-alvo que devem estar bem compreendidas assim como as carências dos produtos concorrentes. Estabelecendo a funcionalidade e estética que o produto deve passar.

Desta forma o significado por meio do design que o mobiliário multifuncional deverá transmitir para o público é: Multifuncionalidade, Praticidade e Aconchego.

A multifuncionalidade afim de melhor aproveitar o espaço do ambiente, utilizando a matéria e dimensão do móvel para uma outra funcionalidade necessária; a praticidade tanto no processo de fabricação, quanto em formas e materiais de fácil limpeza, módulos e espaços que ajudem na organização do cômodo, encaixes presentes para montagem e desmontagem, acessórios e peso pensados no deslocamento da peça; o aconchego estético com formas simples e limpas, espaços para decoração individual, fazendo o produto mais íntimo do usuário.

\subsection{Geração de Alternativas}

Com base nos conceitos gerados a partir de toda a pesquisa de projeto, com a ajuda visual dos painéis e dos requisitos selecionados para atender as necessidades do público-alvo, a metodologia seguiu para a etapa de criação com a geração de alternativas. 
Foram desenhadas a mão algumas ideias iniciais de móveis multifuncionais, pensando como prioridade de função as observadas como carência do usuário: organização, decoração, espaço para estudar.

Após uma matriz de decisão com os requisitos de projeto pontuados com peso (1 desejável e 2 obrigatório) para cada alternativa, avaliando se atende ou não ao requisito ( $1 \mathrm{sim} / 0$ não) sendo somado seu total em seguida para a definição do desenho final e feita a modelagem 3D inicial. Foi selecionado então a alternativa 'Escrivaninha Multifuncional' como modelo final (Figura 10).

Figura 10: Alternativa final desenhada, rendering digital e primeira modelagem 3D.
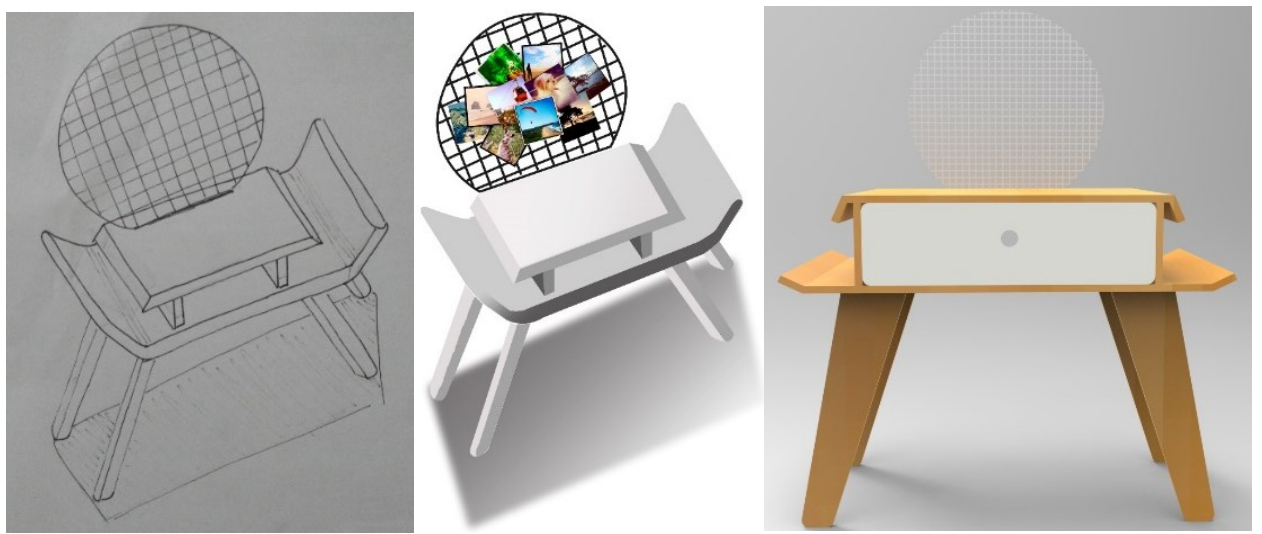

Fonte: Da autora

\section{Resultados}

O modelo de apresentação foi feito em escala reduzida 1:5 utilizando como material o MDF. Cortado na máquina a laser o material possui $2,5 \mathrm{~mm}$ de espessura, foi realizado o empilhamento para chegar na medida desejada de $5 \mathrm{~mm}$. Para o acabamento superficial, foi utilizado a colagem de adesivo (Figura 11), com textura de madeira mais próximo ao rendering digital.

Figura 11: Modelo de apresentação e Ambientação

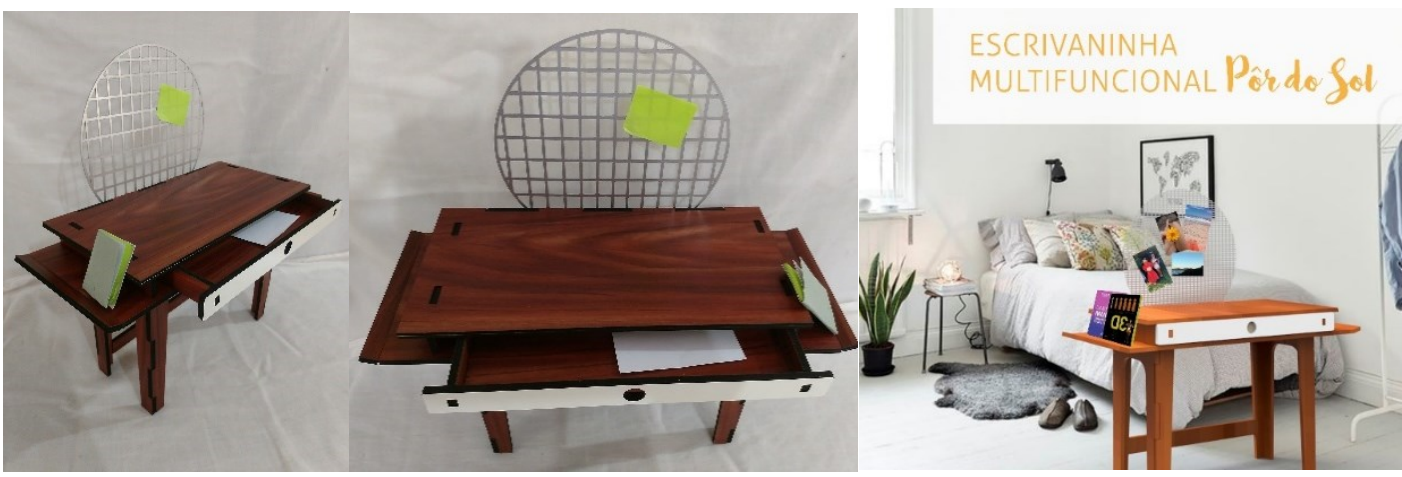

Fonte: Da autora

A escrivaninha 'Pôr do Sol' utilizada como processo de produção o corte por usinagem na 13 Congresso Brasileiro de Pesquisa e Desenvolvimento em Design, Univille, Joinville (SC) 
máquina $\mathrm{CNC}$, e sua montagem e desmontagem é feita por encaixes tornando o processo mais intuitivo e fixação com poucos parafusos. A madeira utilizada é de reflorestamento com espessura de $18 \mathrm{~mm}$ e seu painel de fotos é de alumínio.

O produto desenvolvido tem dimensões e estrutura de fácil produção, com um alto potencial de comercialização em lojas e-commerce onde o cliente pode montar seu móvel em casa. Seus encaixes tornam o processo de montagem e desmontagem mais intuitivo de fácil compreensão, com a utilização de alguns parafusos para fixação final. Seu design e cortes aproveitam melhor o material, possibilitando uma disposição na hora do corte na CNC evitando o desperdício de madeira.

A escrivaninha multifuncional Pôr do Sol tenta trazer ao ambiente compacto e limitador desses apartamentos/casas compactas o frescor e amplitude da natureza através de sua forma remetendo a um fim de tarde. A escolha dos encaixes para montagem e desmontagem foi trazida depois da pesquisa quantitativa do público-alvo onde foi detectado o problema na demora de entrega e espera de um montador de móveis quando feita a compra do produto em loja física, tornando esse processo intuitivo e prático para ser realizado em casa. Além de proporcionar resistência a estrutura do mobiliário. A possibilidade de tornar o produto íntimo do consumidor com o painel de fotos e recados, caracterizando com seu "jeitinho". O design limpo e minimalista foi caracterizado com cores neutras, que procuram se adequar a ambientes diversos.

\section{Conclusão}

Devido à grande procura por ambientes compactos sendo uma forma mais acessível de adquirir o imóvel próprio em relação ao custo versus localização, o design de mobiliário vem se adaptando a essa tendência. Tendo como objetivo ao longo do projeto amenizar a falta de conforto nesses espaços tornando-o aconchegante e criando um mobiliário adequado ao públicoalvo que reside nesses apartamentos e casas reduzidos com ou sem divisórias de cômodos, facilitando o seu dia-a-dia trazendo um produto prático, que ajude na organização, e intuitivo na hora da montagem e desmontagem devido ao problema de demora de entrega das lojas físicas.

Foi visto em uma das etapas da metodologia de Kumar, na pesquisa etnográfica, que o usuário passa mais tempo dentro do quarto e destinado a criação do produto a este espaço.

As necessidades do público encontradas bem como os requisitos de projeto foram trazidas para o resultado final através de formas e materiais. Com linhas arredondas, materiais que facilitam a limpeza, cores clean que se adequam a ambientes diversos e customizável com fotos, objetos. Os encaixes foram pensados a fim de tornar o móvel mais prático e comercializável por lojas e-commerce.

Na etapa de modelagem 3D pode contribuir para a concepção visual e testes em mock-up tornando possível estabelecer as medidas adequadas de acordo com a ergonomia.

Finalizando em um mobiliário compacto que atende as principais funções que o usuário possuía carência. Com possibilidade de aplicação de uma linha de produtos vistos nas alternativas finais, com design e materiais coerentes.

Este tema de projeto pode ser ampliado em outros trabalhos como continuação utilizando necessidades e requisitos encontrados para gerar outras soluções de mobiliário para esses 
espaços.

\section{Referências}

ALVARADO, R.G; BRUSCATO, U.M. Evaluación de Experiencias de Fabricación Digital en la Enseñanza de Arquitectura. In: INTERNATIONAL CONFERENCE ICBL, 3.,2009, Florianópolis. Anais. Florianópolis: UFSC, 2009.

BARROSO, Deise. V. et al. 0 setor de móveis na atualidade: uma análise preliminar. Rio de Janeiro, 2007.

BARRATO, Romullo. $\mathbf{5 0}$ modelos de encaixes em madeira disponíveis para download. Disponível em: <https://www.archdaily.com.br/br/797785/50-modelos-de-encaixes-em-madeira-disponiveispara-download >. Acesso em: 24 nov. 2017.

BAXTER, Mike. Projeto de Produto: Guia prático para o design de novos produtos. São Paulo, 2000.

COSTA-NETO, Waldo Luis et al. Tecnologias de Fabricação Digital para o Desenvolvimento de Artefatos Responsivos. Blucher Design Proceedings, v. 2, n. 3, p. 65-69, 2015.

EDIFICAR. Apartamentos menores são tendência no mercado imobiliário: Consultor Marcus Araújo apresenta demandas do mercado com base em pesquisas. 2017. Disponível em: $<$ https://revistaedificar.com.br/noticias/apartamentos-menores-sao-tendencia-no-mercadoimobiliario/>. Acesso em: 11 abr. 2017.

GORNI, A. A. Prototipagem rápida: o que é, quem faz e por que utilizá-la. Revista do Plástico Industrial. São Paulo: Aranda Editora. Ano III, N 31, março, p. 230-239, 2001.

IIDA, Itiro. Ergonomia projeto e produção. São Paulo: Edgard Blücher, 1998.

LAM, Camila; ZUINI, Priscila. As 60 ideias de negócios que mais dão certo no Brasil: Veja quais tipos de empresas mais sobrevivem no país, segundo dados do Sebrae. 2016. Disponível em: <http://exame.abril.com.br/pme/as-60-ideias-de-negocios-que-mais-dao-certo-no-brasil/>.

Acesso em: 10 abr. 2017.

LIMA, Marco Antonio Magalhães. Introdução aos Materiais e Processos para Designers. Rio de Janeiro: Editora Ciência Moderna Ltda., 2006.

LIMA, Andressa de Souza; TORRES, Pablo Marcel de Arruda. Mobiliário Multifuncional de Descanso para Habitações com Dimensões Reduzidas. Revista de Iniciação Científica, Tecnológica e Artística: Comunicação, Arquitetura e Design, São Paulo, v. 3, p.01-14, 1 set. 2013. Mensal. Disponível em: <http://www.revistas.sp.senac.br/index.php/ic/article/viewFile/493/433>. Acesso em: 18 abr. 2017.

MARCELLINI, Domingos. Manual prático de marcenaria. Rio de Janeiro: Ediouro Publicações S.a., 1997.

MEDEIROS, Ivan Luiz et al. Prototipagem Rápida e Design de Produto Assistivo. Blucher Design Proceedings, v. 1, n. 4, p. 2468-2478, 2014. 
PANERO, Julius; ZELNIK, Martin. Dimensionamento humano para espaços internos. Barcelona: Editorial Gustavo Gili, 2008.

PAZMINO, Ana Veronica. Como se cria: $\mathbf{4 0}$ métodos para design de produto. São Paulo: Blucher, 2013.

PUPO, R. T. A Prototipagem Rápida e a Fabricação Digital: um novo desafio para o ensino de arquitetura. Campinas: [s.n.], 2011.

RBS TV. Indústria de móveis de Santa Catarina aumenta exportações em 2015: Para reconquistar mercado externo, empresas investiram em qualidade. Dólar e euro em alta ajudaram a aquecer a venda do setor no estado. 2015. Disponível em: <http://g1.globo.com/sc/santacatarina/noticia/2015/10/industria-de-moveis-de-santa-catarina-aumenta-exportacoes-em2015.html>. Acesso em: 15 abr. 2017.

KUMAR, Vijay. 101 Design Methods: A Structured Approach for Driving Innovation in Your Organization. Canadá: Wiley, 2012.

ZAP EM CASA. Apartamento pequeno ganha mais destaque na capital paulista. Disponível em: $<$ https://revista.zapimoveis.com.br/apartamento-pequeno-ganha-destaque-emsp/?utm_source=G1_Canal\&utm_medium=link-materia\&utm_campaign=mercado-imobiliario $>$. Acesso em: 26 abr. 2017. 